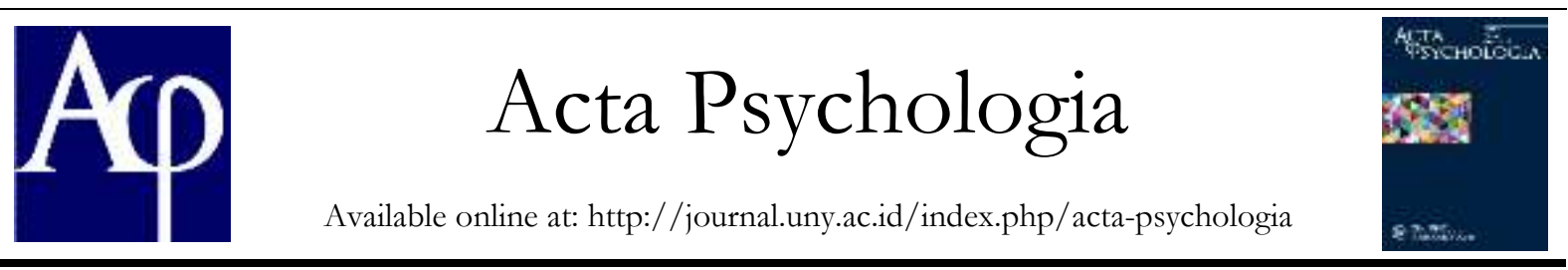

\title{
Hubungan Antara Kontrol Diri dengan Perilaku Konsumtif Melalui Online Shop pada Mahasiswi
}

\author{
Hergita Syi Vadila Sudarisman \\ Jurusan Psikologi, Fakultas Ilmu Pendidikan, Universitas Negeri Yogyakarta; \\ Jl. Colombo No. 1 Sleman Yogyakarta, 55281 \\ shergita26@yahoo.com
}

\begin{abstract}
Abstrak
Kemudahan dalam melakukan belanja secara online memberikan cara baru pada konsumen dalam membeli barang, sehingga hal ini dapat lebih mempermudah konsumen dalam melakukan transaksi dan cenderung berperilaku konsumtif. Sementara itu, kontrol diri merupakan hal penting untuk mengendalikan perilaku konsumtif. Penelitian ini bertujuan untuk mengetahui hubungan antara kontrol diri dengan perilaku konsumtif melalui online shop pada mahasiswi. Penelitian ini menggunakan pendekatan kuantitatif. Subjek dalam penelitian ini adalah mahasiswi Universitas Negeri Yogyakarta angkatan 2016 sebanyak 130 mahasiswi. Metode pengambilan sampel yang digunakan adalah simple random sampling. Instrumen penelitian ini menggunakan dua skala yaitu skala perilaku konsumtif melalui online shop yang terdiri dari 26 item dengan reliabilitas sebesar 0.966 serta skala kontrol diri yang terdiri dari 15 item dengan reliabilitas sebesar 0.920. Hasil analisis data menggunakan Pearson Product Moment menunjukkan bahwa terdapat hubungan antara kontrol diri dengan perilaku konsumtif melalui online shop pada mahasiswi Universitas Negeri Yogyakarta angkatan 2016, dengan nilai korelasi sebesar -0.861 dan signifikansi p < 0.05 yang artinya semakin rendah kontrol diri maka semakin tinggi perilaku konsumtif melalui online shop, begitu pula sebaliknya.
\end{abstract}

Kata Kunci: kontrol diri, perilaku konsumtif, online shop, mahasiswi

\begin{abstract}
The ease of online-shopping provided a new way for consumers to buy goods, which makes it easier for them to make transactions and increases the tendency to be consumptive. However, self control is an important factor for controlling consumptive behavior. This study aims to examine the relationship between self-control and consumptive behavior through online-shopping for college students. This study used a quantitative research approach. The sample in this study were 130 female students of Yogyakarta State University and were taken by simple random sampling. This research instrument used two scales, namely Online Shopping Scale and Self Control Scale. Online Shopping Scale was a 26-items scale with a reliability of 0.966 and the self-control scale, a 15-items scale with reliability of 0.920 . The results of data analysis using Pearson Product-Moment showed that there was a relationship between self-control and consumptive behavior through online-shopping in Yogyakarta State University students class of 2016 student, with a correlation value of -0.861 and a significance of $\mathrm{p}<0.05$, means the lower the self-control, the higher the consumptive behavior through online-shopping for college students, and vice versa.

Keywords: self-control, consumptive behaviour, online-shopping
\end{abstract}

\section{Pendahuluan}

Kecenderungan manusia untuk melakukan konsumsi tiada batas, membeli sesuatu yang berlebihan atau secara tidak terencana merupakan definisi dari perilaku konsumtif.
Sejak dulu hingga kini, tidak dapat dipungkiri bahwa penampilan merupakan salah satu hal yang seringkali mendapat perhatian, khususnya bagi seorang remaja. Menurut Imawati (2013), Terbentuknya perilaku 
konsumtif pada remaja dipengaruhi oleh beberapa faktor. Perilaku konsumtif ini tidak hanya berdasarkan pada kebutuhan, namun juga didorong oleh hasrat dan keinginan. Saat ini perilaku konsumen bukan hanya berdasarkan untuk memenuhi kebutuhan, tetapi juga berdasarkan dorongan untuk mendapatkan suatu sensasi, tantangan, kegembiraan, sosialisasi, dan menghilangkan stres. Selain itu memberikan pengetahuan baru tentang perkembangan trend dan model baru serta untuk menemukan barang yang baik dan bernilai bagi pembeli. Sumartono (dalam Fransisca, 2005) menyebutkan bahwa mode rambut, pakaian, musik dan teknologi baru seperti telepon genggam dikatakan sebagai tren yang dianggap dapat mewakili simbol gaya hidup baru dan lambang prestise dari penampilan masyarakat modern.

Menurut Loudon dan Bitta (1993) remaja adalah sekelompok orang yang mudah terpengaruh oleh pola konsumsi barang yang berlebihan di antaranya pada sektor fashion, teknologi, dan makanan. Selain itu pada usiaremaja merupakan usia orientasi konsumtif, artinya usia remaja merupakan wujud ekspresi dari perilaku eksperimental untuk mencoba hal-hal baru. Hal tersebut didukung oleh pendapat Erickson (dalam Alwisol 2008), dimana usaha mencari suatu hal yang baru tersebut disebut sebagai usaha mencari jati diri mereka.

Teknologi yang berkembang memberi dampak bagi remaja. Gadget canggih dan internet membuat remaja mudah untuk mengakses segala informasi di internet. Produsen dan pebisnis pun semakin banyak menawarkan produknya melalui internet. Konsumen dapat membeli produk melalui internet ini lah yang kemudian disebut belanja online. Belanja online merupakan bentuk berbelanja baru yang tidak memerlukan komunikasi tatap muka secara langsung melainkan dapat dilakukan secara terpisah dimanapun dan kapanpun (Saragih \& Ramdhany, 2012).

Dewasa ini, teknologi mengalami perkembangan yang pesat dalam segala bidang. Salah satu bidang yang mengalami kemajuan pesat adalah bidang sosial media. Penggunaan internet sebagai media akses saat ini telah mendapatkan daya tarik sebagai alat pemasaran yang paling cepat dan revolusioner. Kemajuan tersebut dimaksudkan untuk pemenuhan kebutuhan manusia yang semakin beragam. Kemajuan yang sangat dirasakan perbedaannya adalah adanya situs World Wide Web (WWW) yang telah menghasilkan penciptaan bentuk baru dalam transaksi jual beli secara online. Kini perkembangan teknologi internet memungkinkan konsumen untuk membeliproduk atau jasa dari online shop dan informasi mengenai produk dapat dilihat dari internet (Megawati \& Farida, 2014).

Peneliti melakukan survei mengenai alasan konsumen berbelanja melalui online shop yang dilakukan pada 18 mahasiswi Fakultas Ilmu Pendidikan Universitas Negeri Yogyakartapada tanggal 20 Oktober 2018. Berdasarkan hasil wawancara yang dilakukan oleh peneliti mengenai kategori produk apa saja yang dibeliketika melakukan berbelanja melalui online shop, 14 dari 18 orang atau $77,78 \%$ responden menjawab bahwa kategori yang biasa dibeli ketika berbelanja online shop yaitu kategori fashion. Dari jawaban responden juga menjelaskan bahwa produk dari kategori fashion yang dibeli adalah pakaian, sepatu, tas, aksesoris, dan juga kerudung. Dalamwawancara tersebut juga responden diminta untuk memberikan alasan mengapa memilihberbelanja melalui online shop.

Dari hasil jawaban responden, maka dari jawaban tersebut ditemukan bahwaresponden memilih berbelanja melalui online shop dikarenakan lebih efisien waktu dan tenaga serta harga yang ditawarkan lebih murah dibandingkan dengan di toko. Ketikamembeli melalui online shop, konsumen merasa lebih praktis dan juga efisien dikarenakan tidak perlu untuk menyediakan waktu untuk mengunjungi toko ketika sedang sibuk.Berbelanja melalui online shop juga sudah terdapat detail mengenai ukuran, bahan, dan warna serta ulasan mengenai 
produk, sehingga konsumen cukup mendapat informasi lengkap mengenai produk yang akan dibelinya tanpa harus datang ke toko secara langsung. Proses pembayaran dan pemesanan juga lebih cepat dan juga praktis, sehingga konsumen saat ingin berbelanja bisa dilakukan dimana dan kapan saja. Konsumen juga merasa tidak perlu mengeluarkan biaya ekstra untuk membayar bensin dan juga parkir. Berbelanja online juga seringkali menawaran adanya potongan harga atau diskon kepada konsumen, selain itu juga terdapat promosi yang menarik seperti pembelian gratis produk dan juga pembebasan biaya pengiriman. Hal tersebut membuat berbelanja melalui online shop menjadi lebih murah dirasakan oleh konsumen dan membuat konsumen secara berkala berbelanja melalui online shop dibandingkan dengan di toko.

Responden juga diminta untuk menceritakan mengenai pengalaman saat mereka berbelanja melalui online shop. Pengalaman yang diceritakan responden adalah ketika diamembeli pakaian melalui online shop dikarenakan melihat penawaran potongan harga sebanyak $20 \%$, sehingga membuat responden tersebut tertarik untuk membeli pakaian itu walaupun sebenarnya tidak terlalu membutuhkannya, kemudian responden lain juga bercerita pengalamannya melalui online shop, yaitu saat responden berbelanja dua pakaian namun dikarenakan adanya penawaran gratis biaya pengiriman barang maka responden langsung berniat untuk menambah pembelian barang agar mendapat bonus tersebut. Responden mengatakan bahwa seringkali mereka lebih memilihberbelanja melalui online shop dikarenakan penawaran potongan harga dan juga gratis biaya pengiriman serta proses berbelanja yang lebih efisien sehingga bisa dilakukan kapan dan dimana saja. Selain pengalaman yang baik, responden juga bercerita mengenai pengalaman buruk yang dialami ketika berbelanja online, yaitu adanya perbedaan barang yang diterima dengan barang yang dipesan, kemudian waktu kedatangan barang tidak sesuai dengan estimasi pengiriman sehingga membuat responden menunggu waktu yang lama.

Kemudahan dalam melakukan belanja secara online memberikan cara baru pada konsumen dalam membeli barang, sehingga hal ini dapat lebih mempermudah konsumen dalam melakukan transaksi dan cenderung berperilaku konsumtif. Menurut Averill (1973), adanya kontrol diri menjadikan individu dapat mengarahkan, mengontrol, dan mengatur perilakunya dengan kuat yang pada akhirnya dapat menuju pada konsekuensi positif. Individu yang memilikikontrol diri yang kuat, maka akan mampu membuat pertimbangan prioritas dalam membeli, memilih antara yang sesuai dengan kebutuhan dan yang tidak. Sebaliknya, individu dengan kontrol diri yang lemah makaakan membeli suatu barang tanpa mempertimbangkan prioritasnya.

Berdasarkan penjelasan tersebut, maka peneliti menyadari bagaimana pentingnya penelitian ini sebagai manfaat yang dapat digunakan untuk memperkaya kajian pustaka bagi ilmu Psikologi Konsumen, mengenai bagaimana kontrol diri dapat mempengaruhi perilaku konsumtif berbelanja online serta sebagai referensi bagi remaja dalam melakukan pembelanjaan melalui online shop serta dapat tetap menjaga kontrol diri yang dimiliki. Oleh karena itu, peneliti tertarik untuk melakukan penelitian yang berjudul Hubungan Antara Kontrol Diri dengan Perilaku Konsumtif Melalui Online shop pada Mahasiswi.

\section{Metode Penelitian}

\section{Jenis Penelitian}

Penelitian ini merupakan penelitian kuantitatif.

\section{Waktu dan Tempat Penelitian}

Penelitian ini dilaksanakan di Fakultas Ilmu Pendidikan Universitas Negeri Yogyakarta. Waktu penulisan penelitian dilakukan mulai tanggal 19 Oktober 2018. Selanjutnya, pada tanggal 4-27 Februari 2019 dilakukan proses 
pengambilan data di Fakultas Ilmu Pendidikan Universitas Negeri Yogyakarta. Penelitian ini selesai ditulis pada tanggal 22 Maret 2019.

\section{Populasi dan Sampel Penelitian}

Populasi penelitian ini adalah mahasiswi Fakultas Ilmu pendidikan Universitas Negeri Yogyakarta angkatan 2016 yang berjumlah 645 mahasiswi. Subjek penelitian ini melibatkan 20\% dari keseluruhan populasi yaitu 130 mahasiswi.

\section{Prosedur}

Penelitian ini terdiri dari beberapa tahap. Tahap pertama adalah penyebaran instrumen (skala kontrol diri dan skala perilaku konsumtif melalui online shop) kepada 130 mahasiswi Fakultas Ilmu PendidikanUniversitas Negeri Yogyakarta. Tahap selanjutnya adalah seleksi item dan reliabilitas. Seleksi item dilakukan dengan menggunakan bantuan program SPSS dan melihat angka korelasi item total. Kriteria pemilihan item berdasarkan korelasi item total biasanya menggunakan batasan $\geq 0,30$. Namun, pada penelitian ini kriteria batasan angka korelasi item total diturunkann menjadi $\geq 0,25$. Hal tersebut sesuai pendapat Azwar (2016) bahwa kriteria batasan angka korelasi item total tersebut dapat diturunkan sedikit batasannya menjadi $\geq 0,25$ apabila jumlah item yang terseleksi masih belum mencukupi (Azwar, 2016).

Data, Instrumen, dan Pengumpulan Data

Data diperoleh langsung dari subjek penelitian. Data tersebut diperoleh melalui 2instrumen penelitian yang disebar peneliti kepada 130 mahasiswi. Adapun instrumen yang digunakan yakni skala kontrol diri dan skala perilaku konsumtif melalui online shop. Skala kontrol diri terdiri atas 15 item, sedangkan skala perilaku konsumtif melalui online shop terdiri atas 26 item. Masing-masing subjek mengisi item-item tersebut melalui online form yang disebarkan oleh peneliti. Kemudian setelah diisi data akan sampai kepada peneliti.

\section{Teknik. Analisis Data}

Teknik analisis data yang digunakan dalam penelitian ini adalah analisis deskriptif dan uji hipotesis.

Analisis deskriptif meliputi analisis deskriptif karakteristik subjek dan analisis deskriptif kategori variabel. Uji hipotesis dilakukan dengan melalui analisis pearson product moment.

\section{Hasil Penelitian dan Pembahasan}

Berdasarkan hasil analisis karakteristik subjek, ditemukan data sebagai berikut (dapat dilihat pada Tabel 1.

Tabel 1. Analisis Karakteristik Subjek

\begin{tabular}{lcc}
\hline & $\begin{array}{c}\text { Jumlah } \\
\text { Responden }\end{array}$ & Presentase \\
\hline Usia & & \\
19 tahun & 1 orang & $0,8 \%$ \\
20 tahun & 69 orang & $53 \%$ \\
21 tahun & 53 orang & $41 \%$ \\
22 tahun & 7 orang & $5,2 \%$ \\
& & \\
Jurusan & & $11 \%$ \\
BK & 14 orang & $9 \%$ \\
MP & 12 orang & $7 \%$ \\
PG & 9 orang & \\
PAUD & 31 orang & $24 \%$ \\
PGSD & 24 orang & $18 \%$ \\
PLB & 6 orang & $5 \%$ \\
PLS & 16 orang & $12 \%$ \\
PSIKOLOGI & 18 orang & $14 \%$ \\
TP &
\end{tabular}

Berdasarkan hasil analsisi deskriptif kategori variabel diperoleh data sebagai berikut (Tabel 2 dan Tabel 3)

1. Kontrol Diri memiliki rerata 37,78 dan standar deviasi yang diperoleh adalah 12,693, sehingga kategorisasi yang dihasilkan adalah sebagai berikut:

Tabel 2. Kategorisasi Kontrol Diri

\begin{tabular}{clcc}
\hline $\begin{array}{c}\text { Kategori } \\
\text { sasi }\end{array}$ & $\begin{array}{l}\text { Rumus } \\
\text { kategori } \\
\text { sasi }\end{array}$ & $\begin{array}{c}\text { Jumlah } \\
\text { Responden }\end{array}$ & $\begin{array}{c}\text { Persen } \\
\text { tase }\end{array}$ \\
\hline $\begin{array}{c}\text { Sangat } \\
\text { Tinggi }\end{array}$ & $\mathrm{x}>57$ & 1 & $0,7 \%$ \\
Tinggi & $\begin{array}{l}44<\mathrm{x} \\
\leq 57\end{array}$ & 54 & $42 \%$ \\
& & &
\end{tabular}




\begin{tabular}{lllr} 
Sedang & $\begin{array}{l}31<\mathrm{x} \\
\leq 44\end{array}$ & 24 & $18 \%$ \\
Rendah & $\begin{array}{l}19<\mathrm{x} \\
\leq 31\end{array}$ & 33 & $25 \%$ \\
$\begin{array}{l}\text { Sangat } \\
\text { Rendah }\end{array}$ & $\mathrm{x} \leq 19$ & 18 & $14.3 \%$ \\
\hline
\end{tabular}

2. Perilaku Konsumtif melalui Online Shop memiliki nilai rerata 64.58 dan standar deviasi yang diperoleh adalah 20,019, sehingga kategorisasi yang dihasilkan adalah sebagai berikut:

Tabel 3. Kategorisasi Perilaku Konsumtif

\begin{tabular}{clcc}
\hline $\begin{array}{c}\text { Kategori } \\
\text { sasi }\end{array}$ & $\begin{array}{l}\text { Rumus } \\
\text { kategori } \\
\text { sasi }\end{array}$ & $\begin{array}{c}\text { Jumlah } \\
\text { Responden }\end{array}$ & $\begin{array}{c}\text { Persen } \\
\text { tase }\end{array}$ \\
\hline $\begin{array}{c}\text { Sangat } \\
\text { Tinggi }\end{array}$ & $\mathrm{x}>95$ & 10 & $8 \%$ \\
Tinggi & $\begin{array}{l}75<\mathrm{x} \\
\leq 95\end{array}$ & 36 & $28 \%$ \\
Sedang & $\begin{array}{l}55<\mathrm{x} \\
\leq 75\end{array}$ & 24 & $18 \%$ \\
Rendah & $\begin{array}{l}35<\mathrm{x} \\
\leq 55\end{array}$ & 52 & $40 \%$ \\
Sangat & $\mathrm{x} \leq 35$ & 8 & $6 \%$ \\
Rendah & & & \\
\hline
\end{tabular}

Berdasarkan penelitian yang telah dilakukan, maka dapat diketahui kategori perilakukonsumtif melalui online shop mahasiswi yaitu dari 130 mahasiswi FIP UNY terdapat sebanyak 46 mahasiswi (36\%) memiliki perilaku konsumtif melalui online shop dengan kategorisasi tinggi dan sangat tinggi, sebanyak 24 mahasiswi (18\%) dengan kategorisasi sedang, dan sebanyak 60 mahasiswi (46\%) memiliki perilaku konsumtif melalui online shop dengan kategorisasi rendah dan sangat rendah. Dengan demikian, dapat disimpulkan bahwa perilaku konsumtif melalui online shop pada mahasiswi FIP UNY cenderung rendah. Mengenai kontrol diri mahasiswi, diketahui bahwa mahasiswi FIP UNY terdapat sebanyak 55 mahasiswi $(42,7 \%)$ dengan kategorisasi rendah dan sangat rendah. Dengan demikian, dapat disimpulkan bahwa kontrol diri pada mahasiswi FIP UNY cenderung tinggi dibandingkan dengan perilaku konsumtif melalui online shop yang dimiliki.memiliki kontrol diri dengan kategorisasi tinggi dan sangat tinggi, sebanyak 24 mahasiswi (18\%) dengan kategorisasi sedang, dan sebanyak 51 mahasiswi (38,3\%) memiliki kontrol diri dengan kategorisasi rendah dan sangat rendah. Dengan demikian, dapat disimpulkan bahwa kontrol diri pada mahasiswi FIP UNY cenderung tinggi dibandingkan dengan perilaku konsumtif melalui online shop yang dimiliki.

Penelitian ini memiliki tujuan untuk mengetahui hubungan kontrol diri denganperilaku konsumtif melalui online shop. Hasil penelitian ini menunjukkan bahwa terdapat korelasi negatif yang kuat antara kontrol diri dengan perilaku konsumtif melalui online shop sebesar -0.861 dengan signifikansi 0.00 , artinya semakin tinggi kontrol diri maka semakin rendah perilaku konsumtif melalui online shop, Begitu juga sebaliknya. Hasilpenelitian ini sesuai dengan hipotesis yang telah ditentukan yaitu terdapat hubungan negatif antara kontrol diri dengan perilaku konsumtif melalui online shop pada mahasiswiFIP UNY.

Hasil penelitian ini menunjukkan bahwa kontrol diri berhubungan dengan perilaku konsumtif melalui online shop pada remaja. Peranan penting kontrol diri bagi remaja adalah dalam bentuk menentukan sebuah tingkah laku. Remaja yang memiliki kontrol diri yang rendah seringkali tidak mampu melihat konsekuensi atas tindakan ketika berbelanja, sedangkan remaja dengan kontrol diri tinggi sangat memperhatikan cara-cara yang tepat untuk berperilaku dalah situasi yang bervariasi (Chita, dkk., 2015). Hal ini membuat remaja cenderung terhindar dariperilaku konsumtif melalui online shop. Subjek dalam penelitian ini adalah mahasiswi FIP UNY angakatan 2016 dalam perkembangan masa remaja akhir.

Berdasarkan data yang disajikan dapat disimpulkan bahwa populasiresponden yaitu mahasiswi FIP UNY lebih banyak yang memiliki kontrol diri tinggi dibandingkan dengan kontrol diri yang rendah. Hal ini disebabkan karena Pada masaremaja akhir dapat mencapai periode penemuan diri sehingga remaja dapat memutuskan pilihan mereka sendiri dalam 
berperilaku (Feist \& Feist, 2007).

Teori kontrol diri mengenai faktor internal dari kontrol diri juga mengatakan bahwa semakin bertambahnya usia individu yang matang secara psikologis juga akan mampu mengontrol perilakunya karena telah mampu mempertimbangkan mana hal yang baik danyang tidak baik bagi dirinya.

Dari hasil data penelitian menjelaskan bahwa seseorang memiliki tingkat kontrol diri yang rendah, maka perilaku konsumtif melalui online shop akan rendah. Hal ini didukung dengan pendapat yang dikemukakan oleh munandar bahwa kontrol diri merupakan salah satu kepribadian yang mempengaruhi perilaku seseorang dalam membeli barang dan jasa. Begitu pula dengan pendapat Averill bahwa kontrol diri merupakan kemampuan individu dalam mengendalikan dirinya untuk mencegah atau mengurangi dampak dari dorongan sesaat, sehingga mampu menciptakan keadaan yang lebih baik.

Penelitian yang dilakukan oleh Wijayanti (2013) mengenai Strategi coping menghadapi stress pada mahasiswi program S1 Fakultas Ilmu Pendidikan UNY, hasil dari penelitian tersebut mengatakan bahwa pada hasil strategi coping, dapat diketahui bahwa mahasiswi FIP UNY memiliki strategi coping yang tinggi dengan salah satu aspeknya yaitu kontrol diri sebesar 52,9 \%. Hal ini menjelaskan bahwa mahasiswi FIP UNY memiliki kontrol diri yang tinggi yang ditunjukkan dengan selalu berusaha bersikap tenang dan berkonsentrasi. Penelitian ini mendukung hasil dari penelitian mengenai hubungan antara kontrol diri dan perilaku konsumtif melalui online shop pada mahasiswi FIP UNY yang diketahui bahwa mahasiswi FIP UNY cenderung memiliki kontrol diri yang tinggi dibandingkan dengan perilaku konsumtif melalui online shop.

Sarwono (2003) menjelaskan bahwa perilaku konsumtif melalui online shop cenderung dipengaruhi oleh faktor emosional daripada rasio, karena pertimbangan-pertimbangan dalam membuat keputusan untuk membeli atau menggunakan suatu barang dan jasa lebih menitik beratkan pada status sosial,mode, dan kemudahan daripada pertimbangan ekonomis. Sedangkan kontroldiri menurut Munandar merupakan salah satu sifat kepribadian yang mempengaruhi perilaku seseorang dalam membeli barang dan jasa. Peningkatan terhadap kontrol diri akan disertai pula dengan penurunan perilaku konsumtif melalui online shop.

Peran kontrol diri menurut penelitianAntonides (Fitriana \& Koenjoro, 2009)memiliki peranan yang penting dalam proses membeli suatu barang, karena kontrol diri mampu mengarahkan dan mengatur individu untuk melakukan hal yang positif termasuk dalam membelanjakan sesuatu, Individu yang memiliki kontrol diri tinggi akan mampu mengatur perilaku belanjanya sesuai dengankebutuhan bukan hanya untuk memuaskan keinginan mereka, tidak mudah terpengaruh oleh tawaran dengan diskon yang besar, percaya diri dengan penampilan apa adanya,mampu menata uang lebih efisien dengan membelanjakannya untuk sesuatu yang bermanfaat sebagai asset perilakuPenelitian terkait kontrol diri dan perilaku konsumtif melalui online shop yang juga dilakukan oleh Anggreini dan Mariyanti (2014) menunjukkan bahwa mahasiswi dengan kontrol perilaku yang baik menunjukkan kemampuan untuk mencegah atau menjauhi stimulus berupa dorongan berbelanja, menghentikan stimulus tersebut sebelum waktunya berakhir, dan membatasi intensitasnya. Hasil penelitian tersebut menunjukkan bahwa mahasiswi dengan kontrol perilaku yang baik akan berusaha untuk membimbing, mengatur, dan mengarahkan dirinya untuk membeli barangsesuai dengan kebutuhannya, sehingga tidak mudah melakukan pembelian yang tidak sesuai dengan kebutuhan dan kurang memilikimanfaat. Kemampuan mahasiswi dalam mengendalikan perilakunya akan membantu mahasiswi untuk tidak berperilaku konsumtif melalui online shop. Hal ini mendukung hasil data penelitian yang dilakukan pada mahasiswi FIP UNY yang 
menunjukkan bahwa mahasiswi cenderung memiliki kontrol diri yang tinggi, dan berdampak pada perilaku konsumtif melalui online shop yang dimiliki cenderung rendah.

\section{Simpulan dan Saran}

\section{Simpulan}

Berdasarkan hasil penelitian dan pembahasan, maka diperoleh kesimpulan berdasarkan hasil uji korelasi antara kontrol diri dengan perilaku konsumtif melalui online shop menunjukkan adanya hubungan yang negatif antara kontrol diri dengan perilaku konsumtif melalui online shop pada mahasiswi FIP UNY angkatan 2016yaitu dengan besar $r=-0.861$ dan $p<0.05$. Artinya bahwa semakin tinggi kontrol diri maka semakin rendah perilaku konsumtif melalui online shop dan berlaku sebaliknya. Sumbangan kontrol diri terhadap perilaku konsumtif melalui online shop berdasarkan rumus $\mathrm{r}^{2} \times 100 \%$ yaitu diperoleh hasil sebesar $74 \%$ terhadap perilaku konsumtif melalui online shop, sisanya sebesar $26 \%$ merupakan pengaruh dari faktor lain.

Saran

1. Bagi Masyarakat

Penelitian ini dapat memberikan informasi mengenai bagaimana hubungan kontrol diri dengan perilaku konsumtif melalui online shop, sehingga dapat menjadi acuan bagi masyarakat agar dapat mengontrol kontrol diri yang dimiliki dan juga mencegah kecenderungan berperilaku konsumtif melalui online shop.

2. Bagi Remaja

Hasil dari penelitian ini dapat dijadikan bahan evaluasi bagi remaja akhir, sehingga diharapkan dapat melatih dan meningkatkankontrol dirinya agar dapat mengendalikan kecenderungan perilaku konsumtif melalui online shop.

3. Bagi Pendidik dan Orang tua

Dapat memberikan tambahan ilmu pengetahuan, khususnya untuk Pendidik dan orang tua agar dapat mencegah perilaku konsumtif melalui online shop remaja melalui kontrol diri. Dengan kontrol diri yang baik akan membuat remaja mampu mengendalikan dirinya untuk mencegah atau mengurangi dampak dari dorongan sesaat, sehingga mampu menciptakan keadaan yang lebih baik.

4. Bagi Peneliti Selanjutnya

Dapat menjadikan penelitian ini sebagai referensi untuk melakukan penelitian selanjutnya yang terkait dengan kontrol diri dan perilaku konsumtif melalui online shop. serta dapat meneliti mengenai faktorfaktor yang mempengaruhi remaja dalam berperilaku konsumtif melalui online shop dan tingkat kontrol dirinya. Dapat juga diteliti perbedaan antara responden laki-laki dan perempuan mengenai tingkat perilaku konsumtif melalui online shop dan kontrol dirinya.

\section{Daftar Pustaka}

Ancok, D. (1995). Nuansa psikologi pembangunan. Yogyakarta: Insan Kamil, PustakaPelajar.

Anggraini, R. \& Sulis, M. . (2014). Hubungan antara kontrol diri dengan perilaku konsumtif mahasiswi universitas esa unggul. Jurnal Psikologi, 12(21), 34-42

Anin, F., Rasimin, B., \& Atamini, N. (2008). Hubungan self monitoring dengan impulsive buying terhadap produk fashion pada remaja. Jurnal Psikologi., 35, 181-93.

Mangkunegara \& Anwar, P. (2005). Sumber daya manusia perusabaan. Remaja Rosdakarya:Bandung.

Ardhanari, M. (2013). Memelihara budaya : perspektif masyarakat konsumen dan perilakunya. Orasi Ilmiah Universitas Katolike Widya Mandala Surabaya. Surabaya, Jawa Timur, 1-12. 
Augusty, F. (2006). Metode penelitian manajemen: pedoman penelitian untuk skripsi, tesis dan disertasi ilmu manajemen. Semarang: Universitas Diponegoro.

Averill, J.R. (1973). Personal control over aversive stimuli and its relationship to stress. Psychological Bulletin, University of Massachusetts, 286-303.

Azwar, S. (2014). Metode Penelitian. Yogyakarta: Pustaka Pelajar.

Chita, Regina, C. M., Lydia, D., et al. (2015). Hubungan antara self-control dengan perilaku konsumtif melalui online shop Online shopping Produk Fashion pada Mahasiswi Fakultas Kedokteran Universitas Sam Ratulangi Angkatan 2011. Jurnal eBiomedik (eBm), 3(1), 297-30.

Degibson, S., Sugiarto. (2000). Metode statistika untuk ekonomi dan bisnis. Jakarta : Gramedia.

Elizabeth, H. (1998). Perkembangan anak jilid I. Jakarta : Erlangga

Imawati, I., Susilaningsih, I.E. (2013). Pengaruh financial literacy terbadap Pprilaku konsumtif melalui online shop remaja pada program IPS SMA Negeri 1 Surakarta Tabun Ajaran 2012/2013.

James, F.E. (1994). Perilaku konsumen. Edisi 6 : jilid 1. Penerbit Binarupa Aksara.

Kotler, P., \& Armstrong, G. (2008). Prinsipprinsip pemasaran. Edisi 12. Jilid 1 dan Jilid 2. Jakarta: Erlangga.

Loudon, D.L \& Della, B.A.J. (1993), Consumer behavior: Concepts and application. Singapore: Mc.GrowHill, Inc.

Ma'ruf, H. (2005). Pemasaran ritel. Jakarta: PT. Gramedia Pustaka Utama
Noor, J. (2011). Metodologi penelitian: Skripsi, tesis, disertasi, dan karya Ilmiah. Jakarta: Kencana.

Jannah, B.P. (2005). Metode penelitian kuantitatif. Jakarta: PT Raja Grafindo Persada.

Prastiwi, F. (2018). Hubungan antara kontrol diri dengan perilaku konsumtif melalui online shoppada Ibu Rumah Tangga. Fakultas Psikologi. Universitas Muhammadiyah Surakarta. Surakarta.

Pratiknyo. J. (2008). Perilaku konsumtif melalui online shop terhadap kosmetik. wajah pada mahasiswi ditinjau dari konsep diri dan konformitas. Universitas Katolik Soegijapranata Semarang, Semarang.

Santrock, J.W. (2011). Perkembangan anak edisi 7 jilid 2. Jakarta: Erlangga.

Saragih, H. Ramdhany, R. (2012). Pengaruh intensi pelanggan dalam berbelanja online kembali melalui media teknologi informasi forum jual beli kaskus. Journal of Information System. Jakarta.

Sugiyono. (2013). Metodelogi penelitian kuantitatif, kualitatif dan R\&D. Bandung : Alfabeta.

Sujarweni, V. \& Poly, E. (2012). Statistika untuk penelitian. Yogyakarta: Graha Ilmu.

Sumartono. (2002). Terperangkap dalam iklan (Meneropong Imbas Pesan Iklan Televisi). Bandung: Alfabeta.

Supratiknya. (2014). Pengukuran psikologis. Yogyakarta: Universitas Sanata Dharma.

Wijaya, Megawati \& Farida, J. (2014). Pengaruh rancangan situs, harga, kepercayaan, dan keamanan terhadap pembelian produk 
fashion melalui belanja online. Jurnal Manajemen dan Pemasaran Jasa, 7(2).

Yulihasri, I.M.A. \& $\mathrm{Ku}$ Amir K.D. (2011). Factors that influence customers buying Intention on shopping online. International Journal of Marketing Studies, 3(1), 128-139

Zulganef. (2008). Metode penelitian sosial \& bisnis. Yogyakarta: Graha Ilmu. 